Nevşehir Bilim ve Teknoloji Dergisi TARGid Özel Sayı 96-106 2016

DOI: 10.17100/nevbiltek.210971

URL: http://dx.doi.org/10.17100/nevbiltek.210971

\title{
Karaman Ekolojik Şartlarında M9 Anacına Aşılı Bazı Elma Çeşitlerinin Fenolojik ve Pomolojik Özellikleri
}

\author{
Gülüstan Ünüvar ${ }^{1}$, Lütfi Pırlak ${ }^{2 *}$ \\ ${ }^{1}$ Gıda Tarım ve Hayvancılık Bakanlı̆̆ İlçe Müdürlüğü, Kazımkarabekir, Karaman \\ ${ }^{2}$ Selçuk Üniversitesi, Ziraat Fakültesi, Bahçe Bitkileri Bölümü, Selçuklu, Konya
}

Öz

Bu çalışma Sudurağı-Karaman ekolojik şartlarında M9 anacına aşılı bazı elma çeşitlerinin fenolojik ve pomolojik özelliklerinin tespiti amacıyla yürütülmüştür. Araştırmada Galaxy Gala, Scarlet Spur, Fuji, Pink Lady ve Granny Smith çeşitlerinde tomurcuk kabarması, tomurcuk patlaması, çiçeklenme başlangıcı, tam çiçeklenme, çiçeklenme sonu ve meyvelerin hasat olum tarihleri tespit edilmiştir. Araştırma sonuçlarına göre çeşitlerde tomurcuk kabarması 27 Mart-1 Nisan, tomurcuk patlaması 3-9 Nisan, çiçeklenme başlangıcı 17-23 Nisan, tam çiçeklenme 24-30 Nisan, çiçeklenme sonu 2-8 Mayıs tarihleri arasında gerçekleşmiştir. Çeşitlerde hasat tarihleri 5 Ağustos- 7 Kasım arasında değişmiştir. Çeşitlerin ortalama meyve ağılıkları 197.33 g (Fuji) ile 161.82 g (Pink Lady) arasında bulunmuştur. Suda çözünebilir kuru madde miktarı en fazla olan çeşit Pink Lady (\% 16.54), nişasta miktarı en fazla olan çeşit ise Fuji (\% 2.72) olmuştur. Verimi en fazla olan çeşit Granny Smith olup (16.3 kg/ağaç), bunu Fuji (13.45 kg/ağaç) ve Pink Lady (12.5 kg/ağaç) takip etmiştir. İncelenen çeşitlerin Karaman ekolojik şartlarındaki ekonomik yetiştiriciliği olgunlaşma zamanları ve pazar taleplerine göre tercih edilebilir.

Anahtar Kelimeler: Fenolojik özellikler, pomolojik özellikler, elma çeşitleri, Karaman.

\section{Determination of Phenological and Pomological Characters of some Apple Cultivars Grafted on M9 Rootstock at Karaman Ecological Conditions}

\begin{abstract}
This study was conducted in order to determine the phenologic and pomologic properties of certain apple varieties grafted on M9 rootstock under Sudurağı-Karaman ecologic conditions. Dates of proliferation, bud burst, commencement of blooming, full blooming, end of blooming phases of Galaxy Gala, Scarlet Spur, Fuji, Pink Lady and Granny Smith were identified in this study. According to the findings of the study, the phases took place on these dates respectively: proliferation May 27 - April 1, bud burst April 3-9, first blooming April 17-23, full blooming April 24-30, end of blooming May 2-8. Harvest dates among these varieties are between August 5- November 7. Average fruit weights of these varieties are between 197.33 g (Fuji) and 191.82 g (Pink Lady). While Pink Lady contained total soluble solids matters the most (16.54 \%), Fuji contained the most amylum (2.72 \%) among the varieties. The most fruitful one was Granny Smith (16.3 kg/tree). The others were Fuji (13.45 kg/tree) and Pink Lady (12.5 kg/tree). As a conclusion, these varieties are recommended to be cultivated under the ecologic conditions of Karaman.
\end{abstract}

Keywords: Phenological characters, pomological characters, apple cultivars, Karaman

"e-mail: lpirlak@hotmail.com 


\section{Giriş}

Elma günümüzde Antarktika hariç bütün kıtalarda, ılıman iklime sahip bölgelerde ve tropik bölgelerin yüksek rakımlı yerlerinde yetiştiriciliği yapılan bir meyve türüdür [1].

Ülkemiz diğer tarım ürünlerinde olduğu gibi meyvecilik yönünden de gen merkezi durumunda olup, birçok meyve tür ve çeşidi bakımından oldukça zengindir. Birçok meyve türünün anavatanı olan ülkemiz, elmanın da anavatanları arasında gösterilmektedir [2].

Elma tarımı için ekolojik şartların son derece uygun olduğu Karaman'da pazara yönelik elma üretimi 1950’li yıllarda başlamıştır. İlde 1955 yılında 30 ha kapama elma bahçesi mevcut iken, 2014 yılında bu alan 20.797 hektara yükselmiştir. İlde çöğür anacı üzerine aşılı Starking Delicious, Golden Delicious ve Amasya çeşitleri ile başlayan elma yetiştiriciliğinde 1980-1985 yılları arasında çöğür üzerine aşılı spur çeşitlerle kapama elma bahçeleri kurulmaya başlanmıştır. 1990-1995 yıllarında MM106 ve MM111 klon anaçları üzerine aşılı spur çeşitlerin yetiştiriciliğine, 2000 yılından sonra da M9 anacı üzerine aşılı çeşitlerin yetiştiriciliğine başlanmış ve halen ağırlıklı olarak M9 ve MM106 anaçları üzerine aşılı çeşitler ile bahçe tesislerine devam edilmektedir. Karaman ili elma üretiminde 1990’lı y1llarda Türkiye üretiminde söz sahibi konumuna gelmiştir. Gerek ülke ekonomisi gerekse Karaman ekonomisi için elmacılığın payı oldukça büyüktür. Karaman, Türkiye elma üretiminin; yıllara göre değişmekle birlikte \%10-15'ini karşılamaktadır [3].

Birçok ülkede uygun çeşitleri tespit etmek amacıyla, çok sayıda elma çeşidi üzerine fenolojik ve pomolojik incelemeler yapılmaktadır [4]. Ülkemizde de uygun çeşitleri belirlemek ve yetiştiriciliğini arttırmak için çeşitlerin fenolojik ve pomolojik özellikleri belirlenmelidir. İklime bağlı olarak aynı bitkinin gelişme safhalarının zamanı ve süresi bölgelere göre farklılıklar gösterir. Bu safhaların tespiti için yapılan gözlemlere fenolojik gözlem denir. Fenolojik gözlemler üzerine çevre şartlarının büyük etkisi vardır. Bunun için bir bölgede yapılan çalışmadan bütün meyvecilik bölgelerinde uygulanabilir sonuçlar çıkarmak mümkün olmamaktadır. Bu nedenle araştırmaların değişik bölgelerde yapılması gerekmektedir [5]. Bu çalışma ile ülkemizin önemli elma üretim alanlarından olan Karaman ilinde uygun çeşitlerinin belirlenmesi için M9 anacı üzerinde yetiştirilen bazı elma çeşitlerinin fenolojik ve pomolojik özellikleri ile verim ve kaliteleri incelenmiştir.

\section{Materyal ve Metot}

\subsection{Materyal}

$\mathrm{Bu}$ çalışma Karaman ili Merkez ilçeye bağlı Sudurağı kasabasında üreticiye ait bir meyve bahçesinde yürütülmüştür. Denemede materyal olarak 4 yaşında M9 anacı üzerine aş1lı Galaxy Gala, Granny Smith, Pink Lady, Scarlet Spur ve Fuji elma çeşitleri kullanılmıştır. Çeşitler Galaxy Gala, Fuji, Pink Lady ve Granny Smith $90 \mathrm{~cm}$ sıra üzeri ve $4 \mathrm{~m}$ sıra arası; Scarlet Spur ise $60 \mathrm{~cm}$ sıra üzeri $4 \mathrm{~m}$ sıra arası mesafelerde dikilmiştir.

M9 anacı: Çok bodur anaçlar içerisinde bugün dünyada en çok kullanılanıdır. Verimli topraklarda daha iyi gelişirler. Dikimden itibaren ömrü boyunca desteğe ihtiyaç gösterirler. Dikimin hemen ertesi yılı meyve vermeye başlar ve en iyi şartlarda bile boyu $270 \mathrm{~cm}$ 'yi geçmez. Çögürlerin \% 2040’’ kadar gelişirler. Boğaz çürüklüğüne dayanıklı, fakat ateş yanıklığı ve pamuklu bite hassastır [6]. 
Granny Smith: Ağacı zayıf-orta kuvvette, yarı dik-yayvan gelişir, her yıl ve bol ürün verir. Meyvesi orta iri - iri, yeşil zemin üzeri hafif donuk sarı renkli, kalitesi çok iyi olup, sert, çok sulu ve kendine özgü mayhoş bir tadı vardır. Eylül'ün son haftası hasat edilir. Golden Delicious ve Red Delicious en iyi tozlayıcılarıdır. Meyveleri uygun şartlarda soğuk hava depolarında 9 ay saklanabilir [6].

Galaxy Gala: Ağaçları kuvvetli ve yayvan gelişen, yüksek verimli, güzlük olarak en iyi çeşitlerden olup pek çok çeşit içinde dölleyici olarak kullanılır. Meyveleri orta irilikte, sarı zemin üzerine kırmızı renkli ve belirgin boyuna çizgilidir. Meyve eti krem, sert, sulu, aromalı ve tatıdır. Hasat zamanı Ağustos ayının üçüncü haftasıdır [7].

Pink Lady: Ağacı; kuvvetli, dik gelişir, meyvesi; orta iri, sulu, mayhoş-tatlı, aromalı, meyve eti; krem renkli ve sert, meyve kabuk rengi; yeşil sarı zemin üzerine pembe renkli ve çok lentisellidir. Hasat zamanı tam çiçeklenmeden 195-205 gün sonra olup, tozlayıcıları Granny Smith, Red Delicious, Starkrimson Delicious, Gala grubu ve Fuji'dir [7].

Scarlet Spur: Ağacı zayıf ve yarı dik gelişir. Verimli bir çeşittir. Meyvesi konik uzun gövdelidir, meyve kabuk rengi koyu kırmızı, parlak, bazen daha koyu ve mat renkte olup, yüzeyinin \% 95-100'üne yakın kısmı bu renktedir. Erken çiçeklenme eğilimindedir. Red Delicious çeşidinden çok daha erken renklenmeye başlar. Ticari değeri yüksek bir çeşittir. Hasat tarihi Eylül ayının 2. haftasıdır. Tozlayıcıları Golden Delicious, Granny Smith, Gala, Fuji ve Breaburn çeşitleridir [7].

Fuji: Amerikan çeşitleri Red Delicious ve Virginia Ralls Genet arasında yapılan melezleme sonucunda Japonya'da 1930'larda geliştirilmiş̧ir. Ağaçları kuvvetli, yarı dik gelişmektedir. Meyvesi orta iri-iri, tatlı, sulu, yeme kalitesi yüksek, meyve eti krem renkli, sert ve gevrektir. Meyve kabuk rengi sarı zemin üzerine donuk kırmızımsı portakal rengindedir [7].

Karaman ilinde 1960-2012 yılları arasındaki meteorolojik veriler incelendiğinde; ortalama sıcaklık değerinin en yüksek temmuz ayında $\left(23.5^{\circ} \mathrm{C}\right)$, en düşük ise ocak ayında $\left(0.4^{\circ} \mathrm{C}\right)$ olduğu görülmektedir. En yüksek sıcaklık değeri temmuz ve ağustos aylarında $\left(40.4^{\circ} \mathrm{C}\right)$, en düşük sıcaklık değeri ise şubat $\left(-28.0^{\circ} \mathrm{C}\right)$ ve ocak $\left(-26.8^{\circ} \mathrm{C}\right)$ aylarında ölçülmüştür Aylık toplam yağış miktarı ortalaması incelendiğinde ise aralık ayı $45.5 \mathrm{~kg} / \mathrm{m}^{2}$ yağış miktarı ile en fazla yağış alan ay iken, temmuz ayında en az yağış düşmüştür (Tablo 1).

Tablo 1. Karaman ilinin 2012 ylı iklim verileri [8].

\begin{tabular}{|c|c|c|c|c|c|c|c|c|c|c|c|c|}
\hline KARAMAN & Ocak & Şubat & Mart & Nisan & Mayıs & Haziran & Temmuz & A ğustos & Eylül & Ekim & Kasım & Aralık \\
\hline Ortalama & 0.0 & -1.7 & 4.4 & 14.3 & 16.7 & 23.0 & 25.5 & 22.8 & 20.7 & 15.1 & 8.6 & 5.1 \\
\hline Sicaklık $\left({ }^{\circ} \mathrm{C}\right)$ & & & & & & & & & & & & \\
\hline $\begin{array}{c}\text { Ortalama } \\
\text { En Yüksek }\end{array}$ & 4.4 & 3.8 & 10.5 & 21.2 & 22.9 & 30.2 & 32.9 & 30.3 & 29.0 & 22.5 & 13.1 & 9.4 \\
\hline Sicaklık $\left({ }^{\circ} \mathrm{C}\right)$ & & & & & & & & & & & & \\
\hline $\begin{array}{l}\text { Ortalama } \\
\text { En Düșük }\end{array}$ & -3.9 & -6.5 & -1.2 & 6.8 & 10.2 & 14.7 & 17.4 & 15.3 & 11.6 & 8.8 & 4.7 & 1.3 \\
\hline Sicaklık $\left({ }^{\circ} \mathrm{C}\right)$ & & & & & & & & & & & & \\
\hline $\begin{array}{l}\text { Ortalama } \\
\text { Güneșlenme } \\
\text { Süresi (saat) }\end{array}$ & 3.28 & 5.49 & 5.19 & 9.21 & 8.46 & 12.14 & 12.10 & 11.40 & 11.57 & 7.04 & 3.25 & 3.43 \\
\hline $\begin{array}{c}\text { Aylık } \\
\text { Toplam }\end{array}$ & 54.6 & 51.5 & 28.3 & 13.5 & 23.7 & 3.9 & 0.1 & 5.4 & 0.0 & 24.5 & 42.6 & 52.6 \\
\hline Yağıș $\left(\mathbf{k g} / \mathbf{m}^{2}\right)$ & & & & & & & & & & & & \\
\hline $\begin{array}{c}\text { Ortalama } \\
\operatorname{nem}(\%)\end{array}$ & 77.8 & 76.6 & 60.2 & 43.3 & 51.8 & 36.7 & 33.6 & 36.8 & 36.6 & 59.0 & 74.6 & 74.1 \\
\hline
\end{tabular}

Araştırmanın yapıldığı yılın (2012) meteorolojik verileri incelendiğinde aylık ortalama sıcaklık değerinin $25.5^{\circ} \mathrm{C}$ (temmuz) ile $-1,7^{\circ} \mathrm{C}$ (şubat) arasında değiştiği görülmektedir. Ortalama en düşük 
sıcaklık şubat ayında $\left(-6.5^{\circ} \mathrm{C}\right)$ iken en yüksek sıcaklığın temmuz ayında olduğu $\left(32.5^{\circ} \mathrm{C}\right)$ gözlenmiştir. 2012 yılında ilde toplam yağış $300.7 \mathrm{~mm}$ olmuştur. En yağışı lı ay ocak olup, eylül ayında hiç yağış olmamıştır (Tablo 1).

\subsection{Metot}

Denemede kullanılan M9 anacı üzerine aşılı Granny Smith, Galaxy Gala, Pink Lady, Scarlet Spur, Fuji elma çeşitlerinde aşağıdaki özellikler incelenmiştir.

\section{Fenolojik özellikler}

Tomurcuk kabarması: Çiçek tomurcuklarının belirgin bir şekilde kabardığı devredir [9].

Tomurcuk patlaması: Tomurcukların açılıp yaprak uçlarının görüldüğü devredir [9].

Çiçeklenme başlangıcı: Çiçeklerin yaklaşık \% 5'inin açıldığı devredir [9].

Tam çiçeklenme: Çiçeklerin \%60-70' inin açıldığı devredir [9].

Çiçeklenme sonu: Taç yaprakların \%90'dan fazlasının döküldüğü devredir [9].

Hasat tarihi: Meyvenin hasat olgunluğuna geldiği devredir. Meyvelerin çeşide özgü irilik, renk ve tadını aldığı dönemdir [9].

Yaprak dökümü: Yaprakların sararmaya başladığı ve \%90'ının döküldüğü devredir [9].

Etkili sıcaklık toplamı: Çalışmamızda eşik sıcaklık $+7^{\circ} \mathrm{C}$ olarak kabul edilmiştir. Eşik sıcaklığın üzerindeki günlük ortalama sıcaklıktan eşik sıcaklık çıkarılarak günlük ve buradan her fenolojik safha arasındaki gün sayısına göre toplam etkili sıcaklıklar $\left({ }^{\circ} \mathrm{C}\right.$-gün) "gün-derece" olarak hesaplanmıştır [10].

\section{Pomolojik özellikler}

Araştırmada incelenen pomolojik özellikler 10 adet meyvede ortalama olarak tespit edilmiştir.

Meyve ağırlı̆̆ı: Meyve ağılık ölçümleri 0.01 g'a duyarlı hassas terazi ile yapılmış ve ölçümlerin ortalaması gram olarak alınmıştır [11].

Meyve eni: Meyvenin ekvator bölgesindeki en geniş kısmından $0.01 \mathrm{~mm}$ 'ye duyarlı dijital kumpas kullanılarak mm cinsinden bulunmuştur [11].

Meyve boyu: Meyvenin sap çukuru ile meyvenin çiçek çukuru arasındaki mesafenin $0.01 \mathrm{~mm}$ ye duyarlı dijital kumpas ile ölçülmesiyle bulunmuştur [11].

Meyve indeksi: Meyve indeksi, meyve eninin meyve boyuna oranlanması ile hesaplanmıştır [9].

Meyve eti sertliği: Meyve eti sertliği, $11 \mathrm{~mm}$ uçlu el penetrometresi ile ölçülmüştür [11].

Suda çözünebilir kuru madde miktarı: Suda çözünebilir kuru madde miktarı (SÇKM), el refraktometresi ile \% olarak ölçülmüştür [11].

Nişasta miktarı: Nişasta tayini için ekvator bölgesinden düzgünce kesilen meyveler \% 1 'lik iyot çözeltisine batırılmış ve 3 dakika beklenmiş sonrasında 1-10 değerlendirmesine göre nişasta düzeyi tespit edilmiştir [11].

Çekirdek sayısı: Ölçümleri yapılan her çeşide ait meyvelerin çekirdekleri sayılmıştır.

Verim: Her çeşide ait ağaçların verimleri tek tek tespit edilerek elde edilen verilerin ortalamalarının hesaplanması ile elde edilmiştir.

Deneme tesadüf parselleri deneme desenine göre 3 tekerrürlü olarak kurulmuş ve her parselde 10 ağaç incelenmiş̧tir. 


\section{Bulgular ve Tartışma}

\section{Fenolojik Özellikler}

2012 yılında Karaman şartlarında Pink Lady, Scarlet Spur, Galaxy Gala, Fuji ve Granny Smith elma çeşitlerinde fenolojik gözlem sonuçları Tablo 2'de verilmiştir.

\begin{tabular}{cccccccc}
\multicolumn{2}{c}{ Tablo 2. Çeşitlerde fenolojik gözlem tarihleri (2012) } \\
\hline & $\begin{array}{c}\text { Tomurcuk } \\
\text { kabarması }\end{array}$ & $\begin{array}{l}\text { Tomurcuk } \\
\text { patlaması }\end{array}$ & $\begin{array}{c}\text { Çiçeklenme } \\
\text { başlangıcı }\end{array}$ & $\begin{array}{c}\text { Tam } \\
\text { çiçeklenme }\end{array}$ & $\begin{array}{c}\text { Çiçeklenme } \\
\text { sonu }\end{array}$ & $\begin{array}{c}\text { Hasat } \\
\text { tarihi }\end{array}$ & $\begin{array}{c}\text { Yaprak } \\
\text { dökümü }\end{array}$ \\
Pink Lady & 27.Mart & 03.Nisan & 17.Nisan & 24.Nisan & 02.Mayıs & 07.Kasım & 25.Aralık \\
Scarlet Spur & 28.Mart & 06.Nisan & 20.Nisan & 27.Nisan & 05.Mayıs & 30.Ağustos & 15.Kasım \\
Galaxy Gala & 30.Mart & 05.Nisan & 19.Nisan & 25.Nisan & 03.Mayıs & 05.Ağustos & 15.Kasım \\
Fuji & 01.Nisan & 09.Nisan & 23.Nisan & 30.Nisan & 07.Mayıs & 10.Ekim & 20.Kasım \\
Granny Smith & 31.Mart & 07.Nisan & 21.Nisan & 29.Nisan & 08.Mayis & 15.Ekim & 25 Kasım \\
\hline
\end{tabular}

Yapılan gözlemlere göre 2012 yılında en erken tomurcuk kabarması 27 Mart tarihinde Pink Lady ve 28 Mart tarihinde Scarlet Spur, en geç tomurcuk kabarması da 31 Mart tarihinde Granny Smith ve 1 Nisan tarihinde Fuji çeşitlerinde meydana gelmiştir. Pink Lady en erken (17.04), Fuji en geç (23.04) çiçeklenen çeşitler olmuştur. Tam çiçeklenme ilk olarak Pink Lady çeşidinde (24.04) belirlenirken, bu çeşidi Galaxy Gala (25.04) izlemiş, en son Fuji çeşidinde (30.05) belirlenmiştir (Tablo 2.)

Çeşitlerde çiçeklenme süresi, çiçeklenme periyodundaki iklim şartları ile ilgilidir. Özellikle sıcaklık bu yönde en etkili faktör olup, çiçeklenme periyodunda sıcaklıkların yüksekliği çiçeklenme süresini kısaltmaktadır [12].

Ceylan [13], 2006-2007 yıllarında Niğde'de yaptığı çalışmada 2006 yılında çeşitlerde en erken tomurcuk kabarmasının Galaxy Gala ve Mondial Gala çeşitlerinde meydana geldiğini (23 Mart), bu çeşitleri Oregon Spur ve Scarlet Spur (24 Mart), Red Chief ve Super Chief (25 Mart) ve Early Redone (26 Mart) çeşitlerinin izlediğini tespit etmiştir. En geç tomurcuk kabarması, Granny Smith ve Fuji (27 Mart) çeşitlerinde meydana gelmiştir. 2007 yılında ise çeşitlerde en erken tomurcuk kabarması Galaxy Gala ve Mondial Gala çeşitlerinde meydana gelmiş olup (9 Nisan), bu çeşitleri Oregon Spur ve Scarlet Spur (10 Nisan), Red Chief, Super Chief ve Early Redone (11 Nisan) ve Granny Smith (13 Nisan) takip etmiştir. En geç tomurcuk kabarması ise Fuji (14 Nisan) çeşidinde meydana gelmiştir.

Bilgener ve ark. [14], Samsun ekolojik koşullarında yaptıkları çalışmada M9 anacına aşılı Granny Smith çeşidinde tomurcuk patlamasının 24 Mart tarihinde meydana geldiğini belirlemişlerdir. Çiçeklenme zamanı ve periyodu çeşit, anaç, ekoloji ve uygulanan kültürel işlemlere bağlı olarak değişebilmektedir [15]. Burada da en etkili faktörün iklim olduğu düşünülmektedir. Meyve yetiştiriciliğinde yer seçiminde ekstrem sıcaklıklar önemli olduğu gibi büyüme mevsimindeki sıcaklık toplamı da önemlidir.

En erken hasat edilen çeşit Galaxy Gala (5 Ağustos) olurken en geç hasat olgunluğuna gelen çeşit ise Pink Lady (7 Kasım) olmuştur. Yaprak dökümü sırasıyla Scarlet Spur ve Galaxy Gala (15 Kasım) , Fuji (20 Kasım), Granny Smith (25 Kasım) ve Pink Lady (25 Aralık) çeşitlerinde gerçekleşmiştir. 
Tam çiçeklenmeden hasada kadar geçen gün sayısı 102-197 gün arasında değişirken, en uzun olgunlaşma süresi Pink Lady ile Granny Smith, en erken olgunlaşma süresi ise Scarlet Spur ile Galaxy Gala çeşidinde gerçekleşmiştir.

Elma çeşitlerinde tam çiçeklenmeden hasada kadar geçen sürenin 130-144 gün arasında değişebileceği belirtilmektedir [16]. Polat [17], Tokat şartlarında Granny Smith çeşidinde tam çiçeklenmeden hasada kadar geçen süreyi 143-149 gün olarak belirlemiş̧ir. Baytekin [18], Tokat şartlarında yapılan çalışmada çeşitlerde tam çiçeklenmeden hasada kadar geçen süreyi 142 gün (Gala/M9), 135 gün (Red Chief/MM106), 154 gün (Fuji/M9), 156 gün (Granny Smith/MM106) olarak saptamıştır. Granny Smith elma çeşidinde tam çiçeklenmeden hasada kadar geçen sürenin 180-210 gün arasında olduğu bildirilmiştir [19]. Araştırmalarda tam çiçeklenmeden hasada kadar geçen sürenin farklı olması, yetişme yerlerindeki iklim şartlarının farklılığının bir sonucudur. İncelediğimiz çeşitlerde tam çiçeklenmeden hasada kadar geçen gün sayısı değerleri literatür ile uyum içerisindedir.

Fenolojik safhalar arasındaki etkili sıcaklıklar ayrı ayrı hesaplanmıştır. Tomurcuk kabarması ile tam çiçeklenme döneminde (A-B) etkili sıcaklık toplamı isteği en yüksek olan çeşit Fuji ( $70.5^{\circ} \mathrm{C}$-gün) olmuştur. Tam çiçeklenme ile çiçeklenme sonu (D-E) döneminde en yüksek sıcaklık toplamı Pink Lady (949 ${ }^{\circ} \mathrm{C}$-gün) çeşidinde saptanmıştır. Çiçeklenme sonundan hasada (E-F) kadar olan dönemde etkili sıcaklık Pink Lady $\left(2539^{\circ} \mathrm{C}\right.$-gün) çeşidinde en yüksek olarak belirlenmiştir. Çiçeklenme başlangıcından hasada kadar (C-F) geçen sürede en yüksek etkili sıcaklık toplamına ihtiyaç duyan çeşitler sırasıyla Pink Lady (2678. $3^{\circ} \mathrm{C}$-gün), Granny Smith $\left(2466.5^{\circ} \mathrm{C}\right.$-gün), Fuji (2414.2 ${ }^{\circ} \mathrm{C}$-gün), Scarlet Spur ve $\left(1923.4{ }^{\circ} \mathrm{C}\right.$ gün) ve Galaxy Gala (1536.8 ${ }^{\circ} \mathrm{C}$-gün)'dır (Tablo 3).

Tablo 3. Çeşitlerde 2012 yılına ait etkili sıcaklık toplamları ( ${ }^{\circ} \mathrm{C}$-gün)

\begin{tabular}{ccccccc}
\hline \multirow{3}{*}{ Pink Lady } & A-B* & B-C & C-D & D-E & E-F & C-F \\
& 14.6 & 101.5 & 60.5 & 94.9 & 2539 & 2678.3 \\
& 7 gün & 15 gün & 7 gün & 8 gün & 189 gün & 226 gün \\
Scarlet Spur & 44.2 & 98.5 & 71.6 & 90.1 & 1782.5 & 1923.4 \\
& 9 gün & 15 gün & 7 gün & 9 gün & 107 gün & 147 gün \\
Galaxy Gala & 32.9 & 102.7 & 54.1 & 92.7 & 1406.7 & 1536.8 \\
& 6 gün & 15 gün & 6 gün & 8 gün & 94 gün & 129 gün \\
Fuji & 70.5 & 90.0 & 85.6 & 68.8 & 2277.8 & 2414.2 \\
& 8 gün & 15 gün & 7 gün & 7 gün & 155 gün & 192 gün \\
Granny & 54.6 & 94.9 & 91.2 & 90.1 & 2306.5 & 2466.5 \\
Smith & 8 gün & 15 gün & 8 gün & 9 gün & 160 gün & 200 gün \\
\hline *Tomurcuk kabarmasi(A), Tomurcuk patlaması(B), Çiçeklenme başlangıc1 (C), Tam çiçeklenme(D), Çiçeklenme sonu (E), Hasat(F)
\end{tabular}

Sonuç olarak, Karaman ekolojisinin sıcaklık birikimleri ve çeşitlerin sıcaklık toplamı isteklerini dikkate aldığımızda, çeşitlerin sıcaklık ihtiyaçlarının karşılandığı görülmektedir. Elde ettiğimiz sonuçlar değişik bölgelerde meyve bahçesi kuracak yetiştiricilere çeşit seçiminde yol gösterecektir.

\section{Pomolojik Özellikler}

Çeşitlere ait meyve özellikleri Tablo 4'de verilmiştir. Meyve ağırlı̆̆ en az olan çeşit Pink Lady (161.82 g) en fazla olan çeşit ise Fuji (197.33 g) olarak belirlenmiştir. Baytekin [18], Tokat şartlarında yaptığı çalışmada elma çeşitlerinde meyve ağılıklarını 186.06 g (Granny Smith/M9), 235.80 g (Red Chief/MM106), 280.18 g (Gala/M9), 283.96 g (Fuji/M9) olarak belirlemiştir. Atay [20], Eğirdir şartlarında yaptığı bir çalışmada Galaxy Gala elma çeşidinin ortalama meyve ağırlığını 150.98 g olarak saptamıştır. Polat [17], Tokat şartlarında yapılan bir çalışmada Granny Smith/ M9 çeşidinin ortalama 
meyve ağırlığını 198.79 g olarak saptamıştır. Denemede elde ettiğimiz meyve ağırlığı bulguları literatür bulgularından kısmen farklı bulunmuştur. $\mathrm{Bu}$ farklılık çeşit, anaç, kültürel uygulamalar (gübreleme, sulama vb.) ve meyve tutum oranlarının farklılığından kaynaklanmış olabilir.

Tablo 4. Çeşitlerin pomolojik özellikler

\begin{tabular}{|c|c|c|c|c|c|}
\hline & Pink Lady & Scarlet Spur & $\begin{array}{l}\text { Galaxy } \\
\text { Gala }\end{array}$ & Fuji & Granny Smith \\
\hline Meyve ağırlı̆̆ı (g) & 161.82 & 190.15 & 119.43 & 197.33 & 190.12 \\
\hline Meyve eni (mm) & 119.40 & 78.07 & 63.21 & 78.74 & 77.24 \\
\hline Meyve boyu (mm) & 65.01 & 63.65 & 99.79 & 59.59 & 67.51 \\
\hline Meyve indeksi (mm) & 2.01 & 1.23 & 1.13 & 1.43 & 1.15 \\
\hline Meyve eti sertliği $\left(\mathrm{kg} / \mathrm{cm}^{2}\right)$ & 6.65 & 6.32 & 6.69 & 7.00 & 8.39 \\
\hline SÇKM (\%) & 16.54 & 12.13 & 13.45 & 16.00 & 12.49 \\
\hline Nişasta miktarı (\%) & 2.20 & 1.76 & 2.50 & 2.72 & 2.25 \\
\hline Çekirdek sayısı (adet) & 6.10 & 6.82 & 5.21 & 8.00 & 5.92 \\
\hline
\end{tabular}

Çeşitlerde SÇKM miktarı \% 12.13 (Scarlet Spur) ile \% 16.54 (Pink Lady) arasında bulunmuştur. Gulino [21], elmalarda iyi bir meyve kalitesi için SÇKM değerinin \%11 civarında olması gerektiğini bildirmiştir. İncelediğimiz çeşitlerde SÇKM miktarları bu değerin üzerindedir. Eren ve ark. [11], Eğirdir şartlarında SÇKM miktarlarının Red Chief çeşidinde \%14.33, Mor Spur çeşidinde \%13.67, Oregon Spur çeşidinde \%11.3, Scarlet Spur çeşidinde \%10.20 olduğunu tespit etmişlerdir. Akçay ve Hamarat [22], Konya şartlarında yetiştirilen Altın çekirdek elma çeşidinde SÇKM değerinin \%15.75; Karlıdă̆ ve Eşitken [23], Erzurum şartlarında elma çeşitlerinde SÇKM değerlerinin \% \%.10-13.80 arasında olduğunu tespit etmişlerdir. Meyvelerde ŞCKM değerlerinde ortaya çıkan kısmi farklılıkların meyvenin ağaç üzerindeki konumundan, değişik anaç kullanımından, kültürel uygulamalardan ve ekolojik şartlardan kaynaklandığı düşünülmektedir. Ayrıca anaçların kuvvetine bağlı olarak SÇKM miktarının değiştiği bildirilmektedir [24].

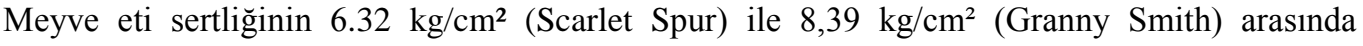
değiştiği saptanmıştır. Kaynaş ve Karaçalı [25], Yalova şartlarında Granny Smith çeşidinde meyve eti sertlik değerini 7.5-8.0 kg/cm² olarak bulmuştur. Öz ve Bulugay [26], Yalova şartlarında Granny Smith çeşidinde meyve eti sertliğinin, hasat tarihinde $7.90 \mathrm{~kg} / \mathrm{cm}^{2}$ olduğunu belirlemişlerdir. Farklı yerlerde yapılan çalışmalarda meyve eti sertlikleri birbirinden farklı bulunmuştur. Bu farklılığın kültürel uygulamalardan, çeşit, anaç, iklim ve toprak özelliklerinden kaynaklandığı düşünülmektedir.

Bulgulara göre çekirdek sayısı en az olan çeşit Galaxy Gala (5.21), en fazla olan çeşit ise Fuji (8.00) olmuştur (Tablo 4). Meyvedeki çekirdek sayısı ile meyve ağırlığı arasında pozitif ilişki araştırıcılar tarafından tespit edilmiştir [27, 28]. Yaptığımız çalışmada ortalama meyve ağırlığı Fuji çeşidinde en fazla (197.33) olmuştur bu da bize çekirdek sayısı-meyve ağırlığı arasındaki ilişkinin literatürdeki yerini doğrulamaktadır.

Nişasta miktarı en fazla Fuji çeşidinde (\% 2.72) olup bunu Galaxy Gala çeşidi (\% 2.50) takip etmektedir. Ceylan [13] tarafından yapılan çalışmada elma çeşitlerinde nişasta miktarları 2006 yılında \% 1.82 (Early Redone) ile \% 2.62 (Fuji); 2007 yılında ise \% 1.97 (Scarlet Spur) ile \% 3.00 (Galaxy Gala) arasında bulunmuştur. Birçok faktörün nişasta miktarı üzerinde etkili olması nedeniyle farklı elma çeşitleri için bölgesel değerler önerilmektedir [29]. 


\section{Verim}

Araştırmada 2012 yılında ağaç başına ortalama verim değerleri Tablo 5’te verilmiştir. Ağaç başına verimler $10.84 \mathrm{~kg} /$ ağaç (Galaxy Gala) ile $16.30 \mathrm{~kg} / \mathrm{ağaç} \mathrm{(Granny} \mathrm{Smith)} \mathrm{arasında} \mathrm{bulunmuştur.}$

Tablo 5. Çeşitlerde verim değerleri

\begin{tabular}{ll}
\hline Çeşit & Verim (kg\ağaç) \\
Pink Lady & 12.50 \\
Scarlet Spur & 11.25 \\
Galaxy Gala & 10.84 \\
Fuji & 13.45 \\
Granny Smith & 16.30 \\
\hline
\end{tabular}

Soylu ve ark. [30] tarafından Bursa'da yapılan bir çalışmada MM106 anacına aşılı çeşitlerin ilk 7 verim yılı sonuçlarına göre, Granny Smith çeşidinin ağaç başına ortalama verim (26.39 $\mathrm{kg} / \mathrm{ağaç})$ bakımından ilk sırada yer aldığı tespit edilmiştir. Baytekin [18], Tokat şartlarında yaptığı çalışmada ağaç başına verimi Gala çeşidinde $27.74 \mathrm{~kg}$, Granny Smith çeşidinde $12.02 \mathrm{~kg}$, Red Chief çeşidinde $12.02 \mathrm{~kg}$ ve Fuji çeşidinde ise $20.04 \mathrm{~kg}$ olarak bulmuştur.

Elde ettiğimiz verim değerleri literatür verilerinden farklı bulunmuştur. Elma ağacının verimi bahçenin bulunduğu yere, yöreye göre büyük bir değişiklik göstermektedir. Birim alana üretilen elma miktarı sadece çeşit ve anacın genetik yapısından değil aynı zamanda sulama, toprak işleme, budama, seyreltme, gübreleme, hastalık ve zararlıların kontrolü gibi bahçede yapılan kültürel uygulamalardan da önemli oranda etkilenmektedir. Bir bahçede meyve verimi değerlendirmede erken meyveye yatma önemli bir kriterdir. Örneğin, bodur gelişen anaçlar üzerine aşılanan çeşitlerin kuvvetli gelişen anaçlar üzerine aşılanan aynı çeşitlere göre daha erken ürüne başladıkları değişik çalışmalarda ifade edilmiştir [31, 32].

\section{Sonuç}

Galletta ve Himelrick [33], meyvelerde büyüme, gelişme ve olgunlaşmanın meyvenin iriliği, kültürel uygulamalar ve sıcaklık ile değişebileceğini; özellikle mevsimler arasındaki sıcaklık değişimleri ile tam çiçeklenmeden hasada kadar geçen gün sayılarının farklılık gösterebileceğini ifade etmişlerdir. Araştırıcılar, belli bir bölge için en iyi adapte olabilecek çeşitlerin seçiminde don olayı meydana gelmeyen günler (büyüme periyodu) ve büyüme derece saatleri toplamının (etkili sıcaklık toplamı) dikkate alınmasını önermişlerdir.

Bol güneşlenebilen, havalanabilen, yeteri kadar hava nemine sahip yerler, elmada çok iyi renk oluşumu sağlar ve elmanın pazar değerini artırır. Gece ile gündüz arasındaki sıcaklık farkının büyük olduğu yayla ve geçit bölgelerinde yetişen elmalar, çok güzel, canlı ve gösterişli renge sahip olur [19]. Karaman da bu özelliklere sahip illerimizin başında gelmektedir ve geniş bir elma üretim potansiyeline sahiptir. Karaman'ın ülkemiz elma üretiminde önemli bir yere sahip olması sebebiyle yetiştirilen elma çeşitlerinin fenolojik ve pomolojik özellikleri belirlenerek performanslarının tespiti büyük önem arz etmektedir.

Karaman ili nispi nem ve güneşlenme süresi bakımından çalışılan elma çeşitlerinin yetiştiriciliği için uygundur. Bu nedenle ilde bu çeşitlerin yetiştiriciliği yaygınlaştırılmalıdır. 
Elma yetiştiriciliğinde verim kaliteyle beraber düşünülmelidir. Aksi takdirde pazarlama alanında büyük problemler yaşanmakta, dolayısıyla üretici ve tüketiciler zarar görmektedirler. Kaliteyi etkileyen en önemli faktörlerden birisi de meyve ağırlığıdır. Pomolojik özellikler incelendiğinde Granny Smith, Fuji ve Scarlet Spur Karaman ekolojisinde en iri çeşitler olurken, Granny Smith, Fuji ve Pink Lady en verimli çeşitler olarak belirlenmiştir. Fenolojik ve pomolojik özellikleri ile verim değerleri sonuçlarına göre Granny Smith ve Fuji elma çeşitlerinin Karaman ekolojisi için uygun olduğu sonucuna varılmıştır. Ancak ilde güneşlenme süresinin fazlalığı ve çeşidin hassasiyeti nedeniyle Granny Smith çeşidinin yetiştiriciliğinde muhakkak surette gölgeleme yapılması gerekmektedir.

\section{Kaynaklar}

[1] Phipps J.B., Robertson K.R., Smith P.G., Rohrer J.R., “A checklist of the subfamily Maloideae (Rosaceae)” Canadian Journal of Botany, 68, 2209-2269, 1990.

[2] Ülkümen L., “Malatya’nın Mühim Meyve Çeşitleri Üzerinde Morfolojik, Fizyolojik ve Biyolojik Araştırmalar”, Yüksek Ziraat Enstitüsü Çalışmaları, Sayı: 65, Ankara, 1938.

[3] Anonim, “Gıda Tarım ve Hayvancılık Bakanlığı Karaman İl Müdürlüğü Verileri” 2014.

[4] Nenadovic-Mratinic F., “Autohtonous apple varieties in the Slovenska Pozega Regio”. XXIII. International Horticulture Congres. Abstracts of Contributed Papers. I. Oral, August 27Septembre I. Frienze. No: 4009. 1990

[5] Özbek S., “Özel Meyvecilik (Kışın Yaprağını Döken Meyve Türleri)”, Çukurova Üniversitesi Ziraat Fakültesi Yayınları, 128, 1978

[6] Özçağıran R., Ünal A., Özeker E., İsfendiyaroğlu M., "Ilıman İklim Meyve Türleri (Yumuşak Çekirdekli Meyveler)”, Ege Üniversitesi Ziraat Fakültesi Yayınları, Cilt:2, No: 556, 2004

[7] Akgül H., Dolunay E.M., Özongun S., Özyiğit S., Atasay A., Demirtaş İ., Pektaş M., Öztürk G., Karamürsel Ö.F., Sesli Y., Göktaş A., Gür İ., Sarısu H.C., Karaarslan Z., "Meyve Çeşit Kataloğu”, Eğirdir Bahçe Kültürleri Araştırma Enstitüsü, Isparta, 223s, 2005

[8] Anonim, 2012., www.meteoroloji.org.tr [Ziyaret Tarihi: 22.01.2012]

[9] Burak M., Büyükyılmaz M., Öz F., "Marmara Bölgesi için ümitvar elma çeşitlerinin seçimi” Bahçe, 27, 107-119, 1998

[10] Ryugo K., “Fruit Culture, Its Science and Art”. John Wiley and Sons, New York, 344, 1988

[11] Eren İ., Özongun Ş., Bayav A., Karakuş A., "MM106 anacı üzerine aşı1ı Starkrimson Delicious elma çeşidi ve bazı mutantlarının kalite kriterleri bakımından yarıştırılması" III. Bahçe Ürünlerinde Muhafaza ve Pazarlama Sempozyumu, Antakya-Hatay, 283-288, 2005

[12] Shoemaker J.S., “General Horticulture”, J.B. Lippincott Company, USA, 464 p. 1952

[13] Ceylan F.B., "Bodur ve Yarı Bodur Anaçlar Üzerine Aşılı Bazı Elma Çeşitlerinin Niğde Ekolojik Şartlarında Fenolojik ve Pomolojik Özelliklerinin Tespiti”, Selçuk Üniversitesi Fen Bilimleri Enstitüsü, Yüksek Lisans Tezi, Konya, 2008

[14] Bilgener Ş., Akbulut M., Kaplan N., "Samsun koşullarında elma yetiştiriciliğinde çeşit/ anaç dikim sıklığı kombinasyonlarının saptanması üzerinde bir araştırma”, Türkiye IV. Bahçe Bitkileri Kongresi, S:223, Antalya, 2003 
[15] Facteau T.J., Rove K.E., Chestnut N.E., "Frimness of sweet cherry fruit following grow in New York”, Proceedings of American Society for Horticultural Science, 57, 169-178, 1986

[16] Ingle M., D'souza M.C., "Fruit characteristic of "Red Delicious" spple strains during maturation and storage”, Journal of American Society for Horticultural Science, 114, 776-780, 1986

[17] Polat M., “Tokat Koşullarında Farklı Gelişme Kuvvetlerine Sahip Anaçlar Üzerine Aşılanmış Elma Çeşitlerinin Fenolojik ve Pomolojik Özellikleri Üzerine Bir Araştırma”, Gaziosmanpaşa Üniversitesi Fen Bilimleri Enstitüsü, Yüksek Lisans Tezi, Tokat, 1997

[18] Baytekin S., Akça Y., "M9 elma anacı üzerine aşılı farklı elma çeşitlerinin performanslarının belirlenmesi”, Gaziosmanpaşa Üniversitesi Ziraat Fakültesi Dergisi, 28, 45-51, 2011

[19] Westwood M. N., “Temperate-Zone Pomology, Physiology and Culture”, Third Edition, Timber Press, Portland, Oregon, 523 p. 1995

[20] Atay E., “MM106 Anacı Üzerine Aşılı Bazı Elma Çeşitlerinde Meyve Büyümesi ve Gelişimini İncelenmesi”, Selçuk Üniversitesi Fen Bilimleri Enstitüsü, Yüksek Lisans Tezi Konya, 34-35, 2007

[21] Gulino F., "Refractometric trials on Golden Delicious from alto adige”, Horticultural Abstracts, 56, 327, 1986

[22] Akçay M.E., Hamarat N., "Konya yöresinde yetiştirilen Altın çekirdek elmasının pomolojik özellikleri ve döllenme biyolojisi üzerine araştırmalar”, Yumuşak Çekirdekli Meyveler Sempozyumu, Yalova, 77-821997

[23] Karlıdă̆ H., Eşitken A., "Yukarı Çoruh Vadisinde yetiştirilen elma ve armut çeşitlerinin bazı pomolojik özelliklerinin belirlenmesi”, Yüzüncü Yıl Üniversitesi Ziraat Fakültesi, Tarım Bilimleri Dergisi, 16 93-96, 2006

[24] Daugaard H., Grauslund J., Callesen O., “The effect of rootstock on yield and quality of apples cv. Mutsu”. Agri-Food Quality II, The Royal Society Chemistry, Thomas Graham House, Science Park, Milton Road, Cambridge CB4 OWF, UK, p 377, 1999

[25] Kaynaş K., Karaçalı İ., "Study on maturity standarts and storage potential of Granny Smith variety of apples grown in Yalova”, Turkish Journal of Agriculture and Forestry, 14, 465-474, 1990

[26] Öz F., Bulugay A. N., "Marmara Bölgesi için ümitvar elma çeşitleri II”. Bahçe, 11, 10-22, 1982

[27] Stoll K., “External quality characteristic of apples Besseres” Obstbau, 30, 244-245, 1985

[28] Eltez M., "Niğde Yöresinde Üstün Özellikli ve Özellikle Meyve Periyodisitesi Göstermeyen Amasya Tiplerinin Seleksiyonu” Çukurova Üniversitesi, Fen Bilimleri Enstitüsü, Doktora Tezi, Adana, 234 s. 1983

[29] Kaynaş K., "Doğu Marmara Bölgesinde Yetiştirilen Önemli Elma Çeşitlerinin Depolama Olanakları Üzerinde Araştırmalar”, Ege Üniversitesi, Fen Bilimleri Enstitüsü, Doktora Tezi, İzmir,227 s. 1987

[30] Soylu A., Ertürk Ü., Mert C., Öztürk O., "MM106 anacı üzerine aşılı elma çeşitlerinin Görükle koşullarındaki verim ve kalite özelliklerinin incelenmesi” Uludă̆ Üniversitesi, Ziraat Fakültesi Dergisi, 17, 57-65, 2003 
[31] Way R.D., Aldwinckle R.C., Rejman A., Sansavini S., Shen T., Watkins R., Westwood M.N., Yoshida Y., “Apples”. Genetic Resources of Temperate Fruit and Nut Crops. 5-6, 1990

[32] Antognozzi E., Proietti P., Famiani F., "Effect of rootstocks and training system on growth and yield of two apple cultivars” Acta Horticulturae, 349, 187-190, 1993

[33] Galletta G.J., Himelrick D.G., “Small Fruit Crop Management” Prince Hall, Englewood, Clifts, New Jersey, 1990 